University of Puget Sound

Sound Ideas

Physical Therapy Research Symposium

Physical Therapy, School of

2017

\title{
The use of Heel Lifts for Individuals with Parkinson's Disease to Improve Postural Stability.
}

Cassandra Repasky

University of Puget Sound

Connor Brown

University of Puget Sound

McKenna McNabb

University of Puget Sound

Jennifer Hastings

University of Puget Sound

Follow this and additional works at: https://soundideas.pugetsound.edu/ptsymposium

Part of the Physical Therapy Commons

\section{Recommended Citation}

Repasky, Cassandra; Brown, Connor; McNabb, McKenna; and Hastings, Jennifer, "The use of Heel Lifts for Individuals with Parkinson's Disease to Improve Postural Stability." (2017). Physical Therapy Research Symposium. 31.

https://soundideas.pugetsound.edu/ptsymposium/31

This Poster is brought to you for free and open access by the Physical Therapy, School of at Sound Ideas. It has been accepted for inclusion in Physical Therapy Research Symposium by an authorized administrator of Sound Ideas. For more information, please contact soundideas@pugetsound.edu. 


\section{The Effect of Heel Lifts on Postural Stability in Individuals with Parkinson's Disease}

Jennifer Hastings; PT, NCS, PhD, Connor Brown; SPT, McKenna McNabb; SPT, Cassie Rapasky; SPT University of Puget Sound; School of Physical Therapy

Introduction:

- Parkinson's Disease (PD) is a progressive, neurodegenerative condition that results in resting tremors, bradykinesia, rigidity, and postural instability. ${ }^{1,2}$

- People with PD develop a standing alignment characterized by flexed hips, kyphotic spine, forward shoulders, forward head, and downward head tilt. Concurrently, this population frequently presents with impaired standing and dynamic balance, decreased muscle strength, slower gait, and slowed anticipatory and reactionary body adjustments. ${ }^{3,4}$

- We propose plantarflexion contractures contribute to postural instability and balance deficits by causing an altered alignment and decreasing the available range for reactive excursion in lower extremity.

- The aim of this study is to determine if accommodating plantar flexion contractures with a heel lift, in people with PD, will improve postural alignment and stability.

Methods:

- Study design: single session pre-test post-test, with subjects as their own control.

- Participants: 32 recruited

- Inclusion criteria: able to ambulate $20 \mathrm{ft}$. without an assistive device, diagnosed with PD

- Exclusion criteria: unable to understand English or had a pre-existing medical condition that would impact their postural stability.

- Outcome measures (recorded with and without heel lifts):

o Sagittal plane posture photo

- Postural sway

- Functional Reach Test (FRT)

Rating of perceived stability

Falls Efficacy Scale (FES)*

- *Measured only once

Table 1: Heel Lift Sizing

\begin{tabular}{|c|c|}
\hline $\begin{array}{c}\text { Dorsiflexion deficit } \\
\text { (degrees) }\end{array}$ & $\begin{array}{c}\text { Adjust-a-lift height of } \\
\text { heel lift (cm) }\end{array}$ \\
\hline Positive to -4 & .5 \\
\hline-5 to -9 & .9 \\
\hline$\leq-10$ & 1.3 \\
\hline
\end{tabular}

Results:

Demographics

- 32 adults with PD (19 male and 13 female)

- Average age of 70 years (range of 43-83).

- Average time since diagnosis was 5.4 years, range $<1-17$ years prior to the study.

- Talocrural DF ROM averaged 0.17 degrees, and ranged between negative 10 and 16 degrees.
Table 2: FES Correlations

\begin{tabular}{|c|c|c|}
\hline FES Subscale Questions & $\underline{\text { r Value }}$ & $\underline{\text { Sig }}$ \\
\hline \#8: Walking around the neighborhood & .46 & 012 \\
\hline \#14: Walking on an uneven surface & .36 & .046 \\
\hline \#15: Walking up and down a slope & .42 & .018 \\
\hline \#16: Going out to a social event & .40 & .030 \\
\hline Total FES Score & .41 & .020 \\
\hline
\end{tabular}

Table 3: Results

\begin{tabular}{|c|c|c|c|c|}
\hline Measurement & Mean change & $\begin{array}{c}\text { Lower } \\
95 \% \mathrm{Cl}\end{array}$ & Upper 95\% Cl & Sig \\
\hline $\begin{array}{c}\text { Posterior pelvis } \\
\text { change }\end{array}$ & $\begin{array}{c}2.3 \mathrm{~cm} \\
\text { anterior }\end{array}$ & $1.4 \mathrm{~cm}$ & $3.1 \mathrm{~cm}$ & .000 \\
\hline $\begin{array}{c}\text { Trunk angle } \\
\text { from horizontal }\end{array}$ & $\begin{array}{c}1.37 \text { degrees } \\
\text { bigger }\end{array}$ & $\begin{array}{c}0.47 \\
\text { degrees }\end{array}$ & 2.55 degrees & .004 \\
\hline $\begin{array}{c}\text { Head tilt angle } \\
\text { from vertical }\end{array}$ & $\begin{array}{c}2.61 \text { degrees } \\
\text { bigger }\end{array}$ & $\begin{array}{c}0.3 \\
\text { degrees }\end{array}$ & 4.93 degrees & .028 \\
\hline $\begin{array}{c}\text { Overall height } \\
1.0 \mathrm{~cm} \text { taller }\end{array}$ & $0.3 \mathrm{~cm}$ & $1.7 \mathrm{~cm}$ & .007 \\
\hline $\begin{array}{c}\text { Functional } \\
\text { reach }\end{array}$ & $\begin{array}{c}2.23 \mathrm{~cm} \\
\text { shorter }\end{array}$ & $0.90 \mathrm{~cm}$ & $3.55 \mathrm{~cm}$ & .002 \\
\hline $\begin{array}{c}\text { Perceived } \\
\text { stability }\end{array}$ & 0.75 & 0.270 & 1.20 & .003 \\
\hline
\end{tabular}

Images 1 \& 2: Significant findings include trunk and head angles at baseline(left), and with the heel lifts in (right).
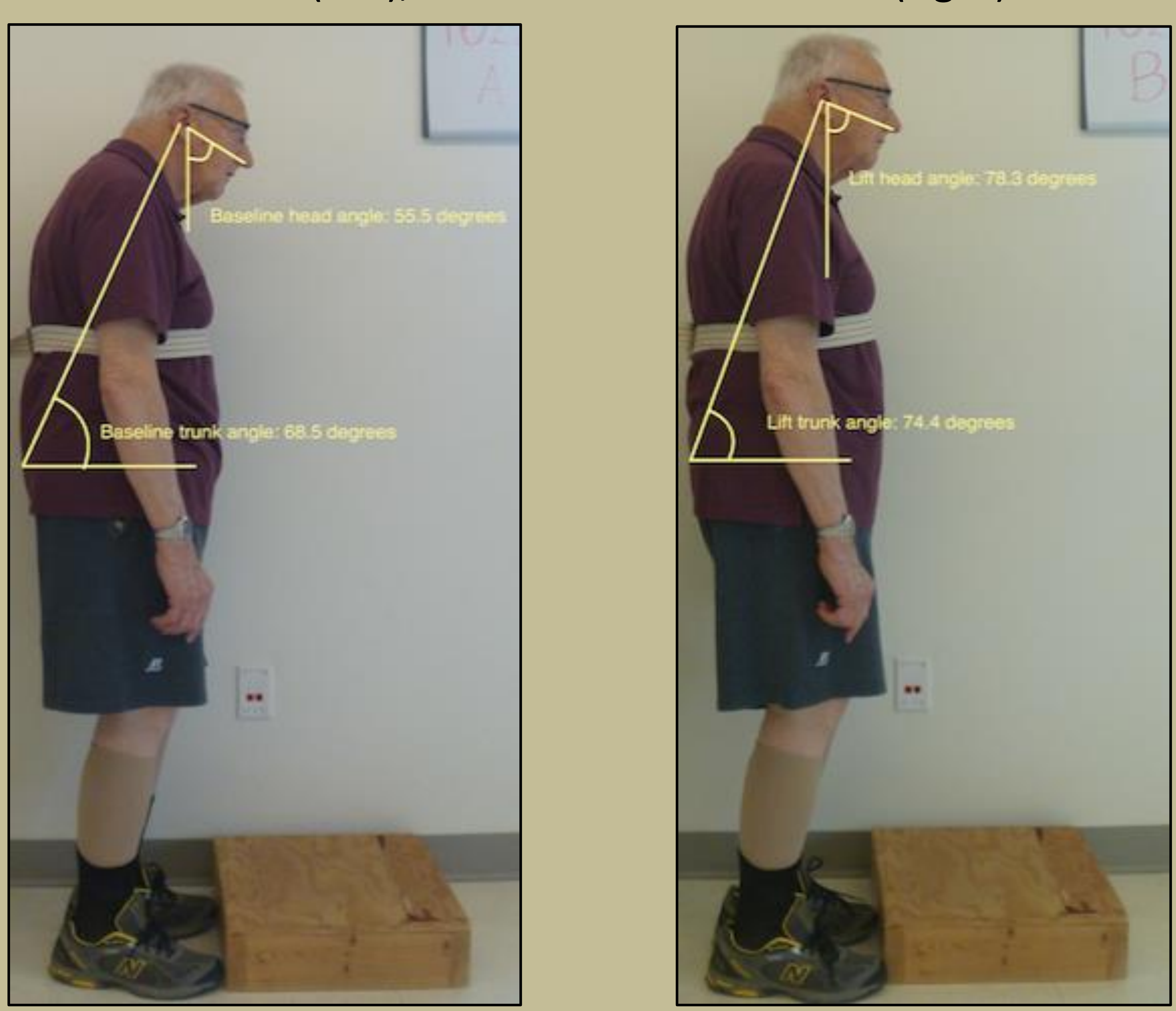

Acknowledgements:

This research study was supported by the School of Physical Therapy
Discussion:

> The heel lifts caused direct changes in participants' posture causing them to stand in an enhanced upright alignment. Enhancements included increased anterior pelvic tilt, trunk angle, and head angle, which resulted in an increase in the participants' standing height

- None of our participants moved into a perfect upright alignment. The remaining postural deficits likely reflect some musculoskeletal shortening or lack of free motion at other proximal joints.

$\diamond$ This theory suggests that heel lifts are a useful treatment to improve postural alignment, however, it should be considered an adjunct

treatment to joint mobilization and muscle lengthening techniques.

$>$ The total FES score correlated with the degree of PF contracture severity $>$ The FES subscales that correlated with the degree of PF contractures all involved ambulation; suggesting the larger the PF contracture, the more difficult ambulatory activities are.

$\diamond$ Both PF contractures and the FES can be utilized to predict the degree of $A D L$ and participation deficits.

$>$ The study found no significant changes in participants' postural sway. There was a significant increase in perceived stability. An increase in perceived stability may lead to decrease in fear of falling; which could ultimately lead to decrease in fall risk, for fear of falling has been shown to be a factor correlated to risk of future falls in the PD population. ${ }^{5,6}$

$\rightarrow$ Standing with Heel lifts $\rightarrow$ Improved plumbline posture $\rightarrow$ Decreased muscular demands of standing $\rightarrow$ Energy conservation

$>$ Our FRT results demonstrated decrease in forward reach measures. It must be noted our intervention resulted in moving the pelvis forward, making rearward pelvic counter balance more difficult; accommodating the PF contracture blocks rearward balance compensation.

$>$ We predict that in addition to postural alignment, dynamic balance should also improve because of the increased excursion available for balance corrections and reactions.

- Our findings are consistent with studies that have shown that heel lifts can improve balance in children with CP and older adults. ${ }^{7,8}$

Future Research:

Long-term follow up to determine if these improved postural effects can be sustained for longer periods of time. Further research looking into the effect of heel lifts on dynamic balance in the PD population.

\section{Conclusion:}

- Heel lifts immediately improved postural alignment and perceived stability in people with PD, but decreased their ability in forward reach test.

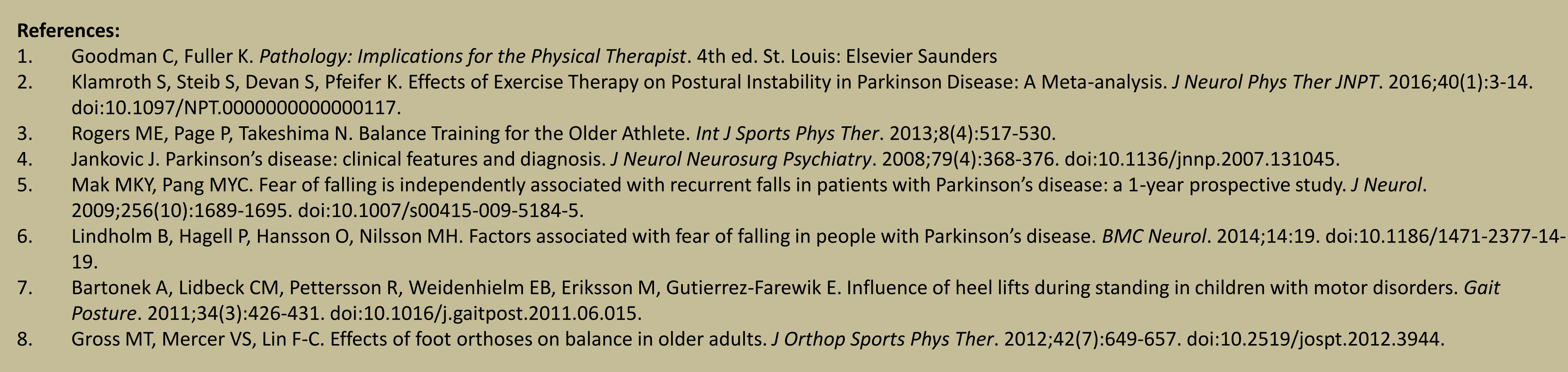

